Distributed Manufacturing 
Hermann Kühnle

Editor

\section{Distributed Manufacturing}

Paradigm, Concepts, Solutions and Examples

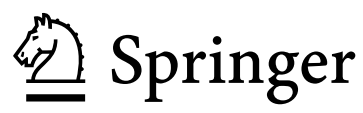




\author{
Editor \\ Hermann Kühnle, Prof. Dr. \\ Otto-von-Guericke-Universität \\ Institut für Arbeitswissenschaft, \\ Fabrikautomatisierung und Fabrikbetrieb (IAF) \\ Universitätsplatz 2 \\ 39106 Magdeburg \\ Germany \\ hermann.kuehnle@ovgu.de
}

ISBN 978-1-84882-706-6

DOI 10.1007/978-1-84882-707-3

Springer London Dordrecht Heidelberg New York

British Library Cataloguing in Publication Data

A catalogue record for this book is available from the British Library

Library of Congress Control Number: 2009936771

(C) Springer-Verlag London Limited 2010

Apart from any fair dealing for the purposes of research or private study, or criticism or review, as permitted under the Copyright, Designs and Patents Act 1988, this publication may only be reproduced, stored or transmitted, in any form or by any means, with the prior permission in writing of the publishers, or in the case of reprographic reproduction in accordance with the terms of licences issued by the Copyright Licensing Agency. Enquiries concerning reproduction outside those terms should be sent to the publishers.

The use of registered names, trademarks, etc. in this publication does not imply, even in the absence of a specific statement, that such names are exempt from the relevant laws and regulations and therefore free for general use.

The publisher makes no representation, express or implied, with regard to the accuracy of the information contained in this book and cannot accept any legal responsibility or liability for any errors or omissions that may be made.

Cover design: eStudioCalamar, Figueres/Berlin

Printed on acid-free paper

Springer is part of Springer Science+Business Media (www.springer.com) 


\section{Foreword}

In recent last years it has become obvious to many companies that, to succeed, they need more effective support for operations and to implement better organisational principles and practices. It is clear that the new industrial world is more complex and more difficult to manage. We need novel organisational and management paradigms in order to uncover and exploit new thinking. Innovation pressures have forced the emergence of Networked Organizations seeking to access innovation resources globally and to secure lasting efficiency competitive advantages.

The networked economy has been enabled and has developed as a result of information and communication technology (ICT) for interorganisational collaboration. Market environments have become much more agile and turbulent and organisations more open under the influence of the rapid advancement of information processing devices and network technologies. Therefore, business strategic and process management, which oversee the overall value creation of products, are the focus of many companies.

Nevertheless, companies have taken rather different approaches to respond to the changes. Some have formed strategic alliances to capture new market opportunities, some have improved existing relationships with their supply network members to enhance the entire value creation supply chains, and some are planning to make changes but in a rather slow manner. Actual cases of industrial implementation of Distributed Manufacturing have shown its effectiveness in responding to the new challenges of the current turbulent and competitive global market, although a number of various barriers still prevent their wider application.

The aim of this book is to promote the adoption of Distributed Manufacturing solutions already experienced by industry players as part of the realisation of the concurrent enterprise (CE) vision, established by the European CE community and represented by CE-NET, the concurrent enterprising network of excellence (CENoE), which aims at promoting top-notch European CE expertise from research, academy and industry. The CE-NET community, facilitated by the European Society of Concurrent Enterprise (ESoCE), has identified new paradigms and approaches to enable the adoption of concurrency principles at the level of distributed product development, networked enterprise and user driven innovation, under the new framework of concurrent innovation. For systematic approach to an ex- 
amination of the whole body of CE knowledge, the issues have been organised into five main areas:

- Human aspects,

- Business model \& organisation,

- ICT infrastructure,

- Product/service development and

- Policy and regulations.

This book provides a substantial contribution to the establishment of a concurrent innovation scientific base and thoroughly covers the first four areas with a stronger focus on technologies, platforms and standards characterising the Distributed Manufacturing context. This book addresses the main barrier that has so far limited the full adoption and exploitation of the emerging paradigms i.e. the issue of managing the complexity of Distributed Manufacturing, and it intelligently suggests how the theory of complex adaptive systems can provide some of the answers. It also sheds new light on the modes by which complex networks can manage parallelism, emergence, behaviour, iteration and encapsulation and in particular how the creative power of individuals and users can be integrated into the distributed processes with a multidisciplinary approach. Although enabled by technology, the initiators of the networked economy are people. Rapid and easy communication brings obvious benefits, but not all the increased communication is value-adding and people have less time to think. It is clear that there are many challenges for companies developing products and services. Some of these have been met; many more require additional efforts. In this book the editor has extracted and synthesized a carefully selected bundle of project results from the European projects PABADIS and PABADIS PROMISE and from closely related research. The invited authors present a number of theories and approaches that, adequately combined, may create suitable concepts for implementing highly workable solutions for Distributed Manufacturing.

In the new context of global industrial networks many concepts have been suggested to improve the base of support for geographically distributed networks and its effective collaboration. Mainly the proposals cover the socio-organisational field; some discuss information and communication technology impacts and options. This book draws from both fields and adds game theoretic and evolutionary elements pulling together principles, aspects and attributes that, even in industry, are mostly considered separate fields and entities that are difficult to unite.

Pick any random spot and you'll find inspiring ideas in this book. The book will serve as more than a detailed record of complex projects. It will provide an invaluable resource for all those wishing to enhance their understanding of changes in the manufacturing world in general and the introduction of new principles in particular. For that reason, I recommend that this book join the set of ready references available to you as together we practice and improve our profession of advanced manufacturing and extended enterprise. 
Rome, April 2009

\section{Roberto Santoro}

President, European Society of Concurrent Enterprising (ESoCE)

Chairman, European Network of Living Laboratories (ENoLL) 


\section{Preface}

"In anything at all, perfection is attained not when there is no longer anything to add, but when there is no longer anything to take away". (Antoine de Saint Exupery)

Profound changes have already occurred in manufacturing within the last decades and the competitive environment for manufacturing will again be significantly different in the next 10 or 15 years. Major developments will occur in a number of different areas of manufacturing such as organisation, collaboration and globalisations resulting in Distributed Manufacturing in many cases. Distributed Manufacturing was originally focused on manufacturing architecture and control within single plants; later it was extended to the virtual manufacture of products and the networked organisation and includes all issues surrounding industrial networks. Key driving forces may be seen in all developments and trends in the fields of information and communication technology (ICT).

The gap between manufacturing automation and social actors' communication should be overcome.

This book represents a synthesis of selected key outcomes from the projects plant automation based on distributed systems (PABADIS) and PABADIS, based product oriented manufacturing systems for re-configurable enterprises (PABADIS'PROMISE), funded by the European Commission. The work on these projects was done through international collaboration over 8 years involving leading researchers as well as leading companies and renowned institutions in manufacturing systems control, embedded systems and network organisation world wide. The results have been consolidated with engineering communities and standardisation bodies.

The volume seeks to anticipate broadly emerging manufacturing structures and the respective information and communication technologies for organisations, their leaders and ICT strategists as well as researchers and technologists facing the challenges of their enterprises' geographical dispersion and network partners' dependencies. To this end, theoretical and application-oriented contributions have been included with a view to achieving the optimum breadth and depth of the relevant subject matter.

The book begins with on overview of methods and systems appropriate for concurrent product development in distributed structures. As many multisite companies and enterprise networks face competition in local contexts while having to keep the enterprises' advantages of common platforms and standards, co-evolution thinking has been chosen as a suitable new theoretical background and idea generator to cope with this growing challenge. The next part discusses new concepts 
of manufacturing management and novel ICT applications which may be unfamiliar to readers and challenge the status quo. As ICT advances are evidently occurring more rapidly at the machinery and equipment level with the respective execution systems, the next large next is devoted to multi-agent systems (MAS) as the central part of the project. The final part, outlining the most recent project results, links the world of agents to products and flexible manufacturing technologies, leading back to the first part and giving substantial clues to further developments as well as hot research topics.

More and more enterprises are faced with the huge, and thus far unseen, challenges of doing manufacturing efficiently in collaborative networks and distributed structures, and operating beyond the consolidated state of the art. For their support and to provide insight into recent developments and emerging concepts, this volume presents a number of ideas, concepts and solution approaches that, when combined in the right way, gives considerable help in responding to those challenges.

Stuttgart, May 2009

Hermann Kühnle 


\section{Contents}

0 Distributed Manufacturing: Paradigms, Concepts, Solutions and Examples...........................................................................................................

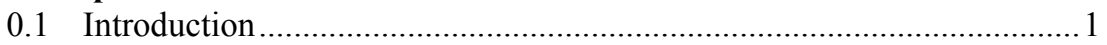

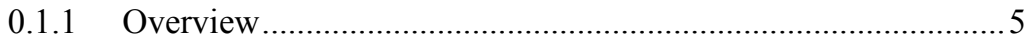

0.1.2 Impacts on Manufacturing Industry ……………………….... 8

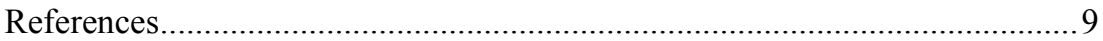

1 The Concurrent Product Development Process .............................................11

1.1 Principles of Product Development....................................................... 12

1.2 Methodology of New Product Development in Extended Enterprises... 13

1.2.1 Product Strategy ....................................................................... 14

1.2.2 Advanced Product Planning........................................................ 16

1.2.3 Product Cost Management ........................................................ 19

1.2.4 Market Analysis ……………………………........................21

1.2.5 Process Coordination ............................................................2.

1.3 The ICT Tools and New Product Development ……............................23

1.3.1 Execution-supporting Tools - Modelling and Simulation Tools....24

1.3.2 Process Planning and Control Tools - Business Process Modelling Tools....................................................................... 25

1.3.3 Cooperation Tools - Computer-supported Collaborative Work Communications ....................................................................2. 26

1.3.4 Management of Information - Product Management Systems ...26

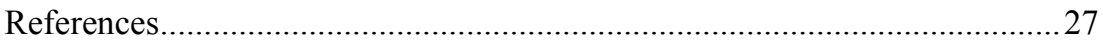

2 A Co-evolutionary Perspective on Distributed Manufacturing .................29

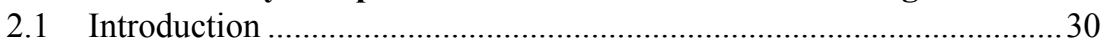

2.1.1 Emergence of Industrial Networks............................................31

2.1.2 Challenges for Contemporary Industrial Networks.....................32

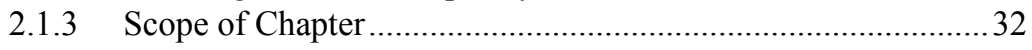

2.2 Evolutionary Perspectives ....................................................................... 34

2.2.1 Co-evolution and Industrial Networks ……………...................35

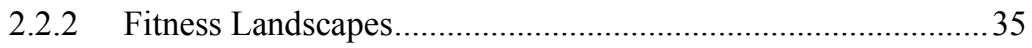

2.2.3 Co-evolution and NK model .................................................... 38

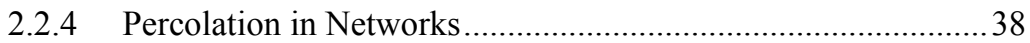




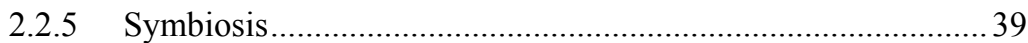

2.3 Distributed Manufacturing and Co-evolution......................................... 40

2.3.1 New Rationales for Distributed Manufacturing ......................... 40

2.3.2 Models for Co-evolution in Collaborative Networks................. 42

2.3.3 Game Theories and Collaborative Networks ............................. 43

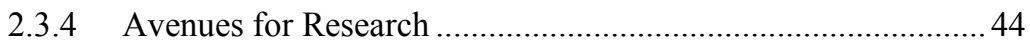

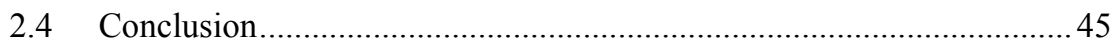

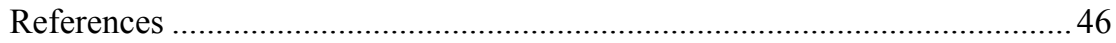

3 Flexibility and Re-configurability in Manufacturing by Means of Distributed Automation Systems - an Overview .........................................551

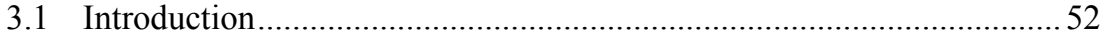

3.2 Current Technology Paradigms.............................................................53

3.2.1 General Technology Application Ideas....................................56

3.3 Challenges in Production Control ...................................................5

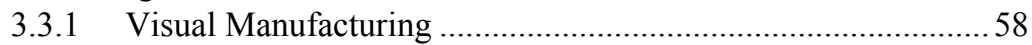

3.3.2 Collaborative Manufacturing …………………….....................59

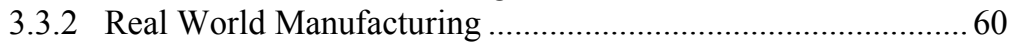

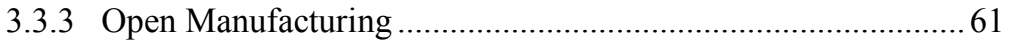

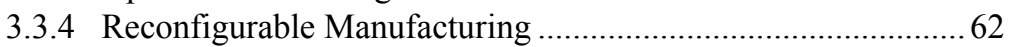

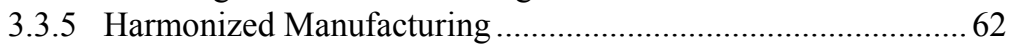

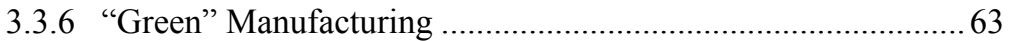

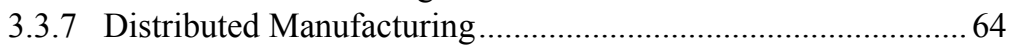

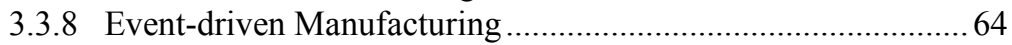

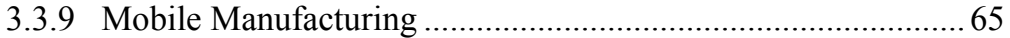

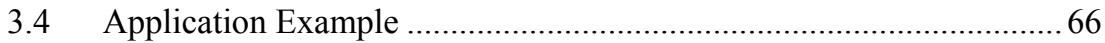

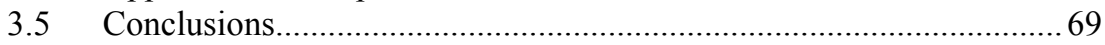

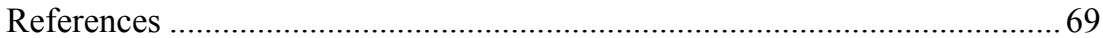

\section{Collaborative Virtual Environments and Immersion in Distributed}

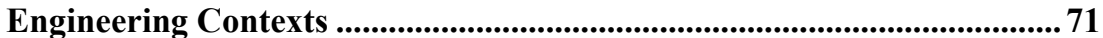

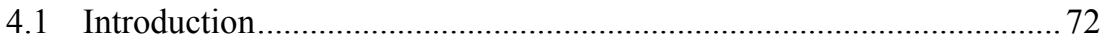

4.2 Related Theories - Terms and Definitions............................................ 73

4.2.1 Collaborative Distance.............................................................

4.2.2 Information and Communication .............................................. 75

4.3 Collaborative Virtual Environment (CVE) - Technologies ......................76

4.3.1 Video Conferencing and Web Conferencing ............................. 78

4.3.2 Instant Messaging and Chat .................................................... 79

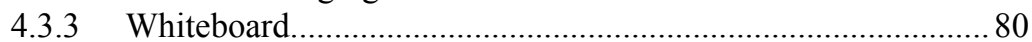

4.3.4 Shared Workspace and Shared Application ................................ 81

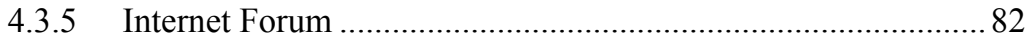

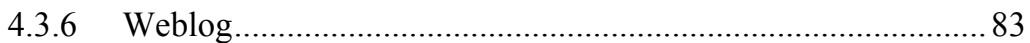

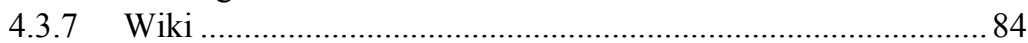

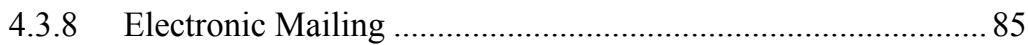


4.3.9 Virtual Reality and Augmented Reality .....................................86

4.3.10 Mobile and Wearable Computing ............................................. 87

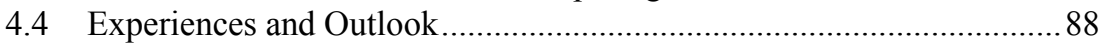

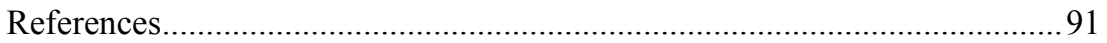

5 Communication Systems as an Integral Part of Distributed Automation Systems...............................................................................................................93

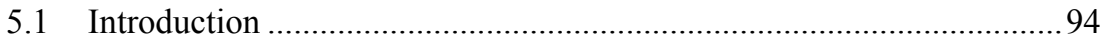

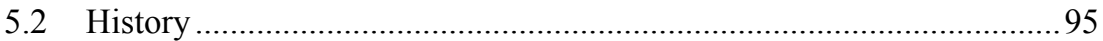

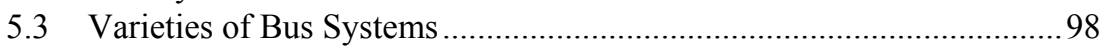

5.3.1 Communication Concepts ......................................................98

5.3.2 Communication Paradigms ................................................... 100

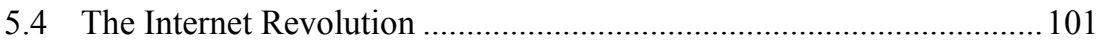

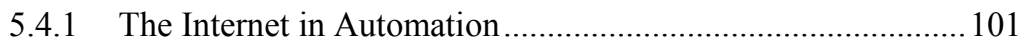

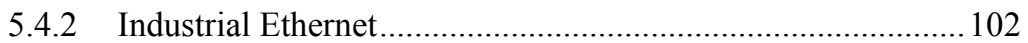

5.4.3 Synchronization in Distributed Systems ..................................104

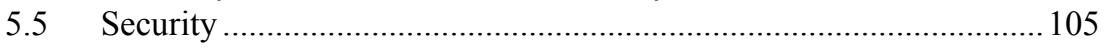

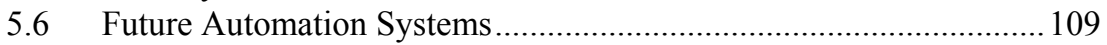

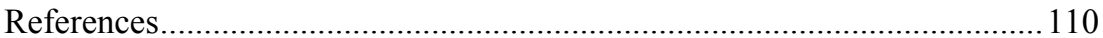

6 Applications of Agent Systems in Intelligent Manufacturing .................113

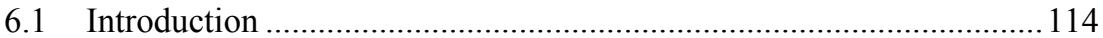

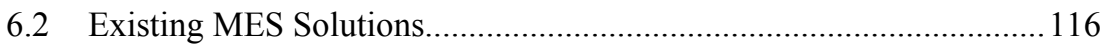

6.3 A Generic Design Pattern for Manufacturing Execution Control.........117

6.4 Distributed Approaches Analysis ………………............................... 119

6.4.1 Resource Holon and Residential Agent ………….................. 120

6.4.2 Order Holon and Product Agent .............................................. 121

6.4.3 Product Holon and Product Agent ……………....................... 121

6.4.4 Stuff Holon and Plant Management Agent ............................. 122

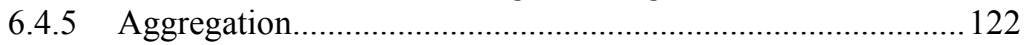

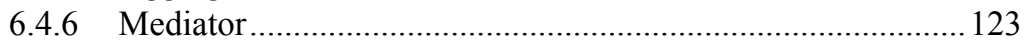

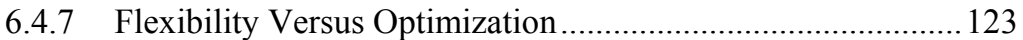

6.5 PABADIS'PROMISE Hybrid Approach.............................................. 124

6.5.1 Resource Handling............................................................. 124

6.5.2 Order Management ............................................................. 125

6.5.3 Supervisory and Supporting Functionalities ............................126

6.5.4 PABADIS'PROMISE Scheduling ......................................... 126

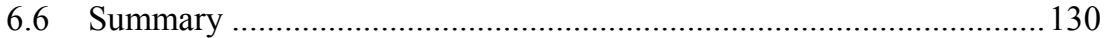

6.7 Practical Implementation Aspects ...................................................... 132

6.7.1 MES Security Architecture .................................................... 132

6.7.2 Radio Frequency Information Technology (RFIT) .................. 134

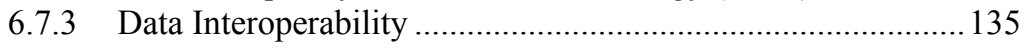

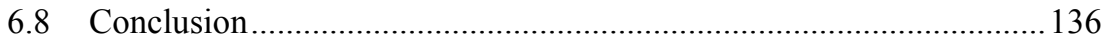

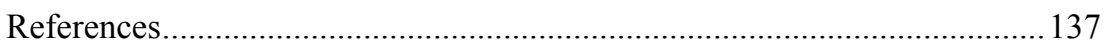


7 Utilization of Advanced Control Devices and Highly Autonomous Systems for the Provision of Distributed Automation Systems ............... 139

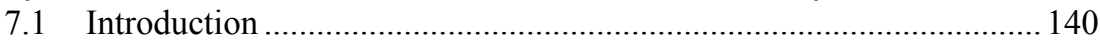

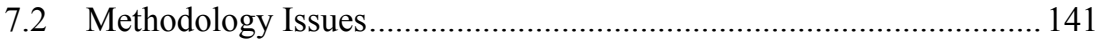

7.2.1 PABADIS'PROMISE High-Level Architecture...................... 142

7.2.2 PABADIS'PROMISE Low-Level Architecture ...................... 144

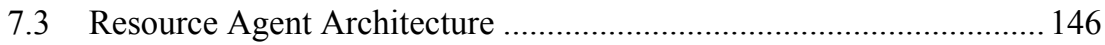

7.3.1 Ability Application ............................................................. 147

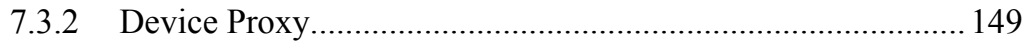

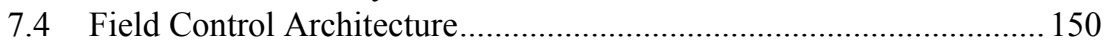

7.4.1 PABADIS'PROMISE Control Device .................................... 150

7.4.2 Device Observer (DO) ........................................................... 151

7.5 Control Device Integration Process ..................................................... 151

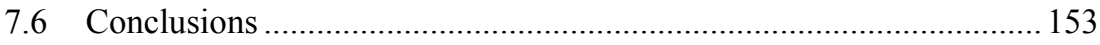



8 Design Patterns for Distributed Control Applications ................................. 155

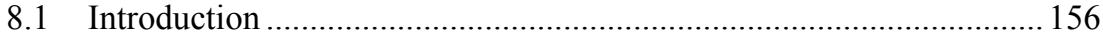

8.2 Requirements for Field Control Systems............................................ 157

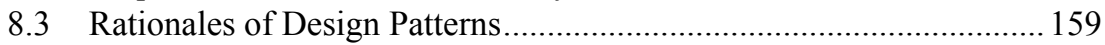

8.4 Existing Design Patterns for Field Control Systems ............................ 160

8.5 Design Patterns for Distributed Field Control Systems ........................... 161

8.5.1 Design Patterns - Distributed Control Applications ................ 161

8.5.2 Design Patterns - Reusability of Control Software Building Blocks ................................................................... 164

8.5.3 Design Patterns - Devices Within Distributed Control

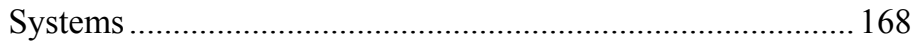

8.6 Application of the Design Patterns Within the PABADIS'PROMISE

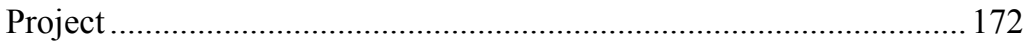

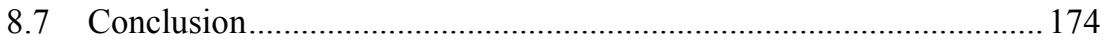

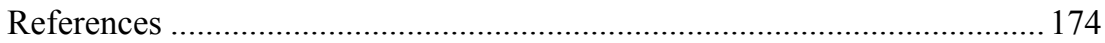

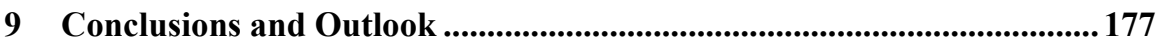

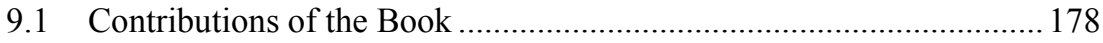

9.1.1 What are the philosophies to manage Distributed

Manufacturing? Which paradigms and metaphors should be emphasised and encouraged for support?

9.1.2 Which disciplines and models are likely to further develop the methods and instruments for Distributed Manufacturing structures? How about the trends in information technology and their effects on coordination and management of interorganisational value chains?

9.1.3 How can companies self position in times of vanishing distinction of organisations from their environment? 
Do organisation theory and management science need to be extended by a number of new chapters covering

decentralised and distributed processes and value chains? ..... 183

9.2 Implications for Practice. 184

Index 187

Bibliography. 


\section{Acronyms}

$\begin{array}{ll}\text { AARIA } & \text { autonomous agents at Rock Island Arsenal } \\ \text { AB } & \text { Ability Broker } \\ \text { ABMEI } & \text { agent-based manufacturing enterprise infrastructure } \\ \text { ADRENALIN } & \text { advanced fractal companies use information supply chain } \\ \text { AOA } & \text { Agent-Oriented Architecture } \\ \text { AR } & \text { augmented reality } \\ \text { BPM } & \text { business process modelling } \\ \text { BSCW } & \text { basic support for cooperative work } \\ \text { CAMAC } & \text { computer-automated measurement and control } \\ \text { CARE } & \text { c-agent runtime environment } \\ \text { CBA } & \text { component-based automation } \\ \text { CCITT } & \text { Comité Consultatif International Télégraphique et } \\ & \text { Téléphonique } \\ \text { CE } & \text { Concurrent Enterprise } \\ \text { CENELEC } & \text { Comité Européen de Normalisation Electrotechnique } \\ \text { CMU } & \text { Co-Operative Manufacturing Unit } \\ \text { CNO } & \text { collaborative network organisation } \\ \text { CSCW } & \text { computer-supported collaborative work communications } \\ \text { CSMA } & \text { carrier sense multiple access } \\ \text { CVE } & \text { collaborative virtual environment } \\ \text { CWE } & \text { collaborative working environment } \\ \text { DBMS } & \text { database management system } \\ \text { DCS } & \text { Distributed Control System } \\ \text { DEDEMAS } & \text { decentralised decision making and scheduling } \\ \text { DF } & \text { Device Function } \\ \text { DFP } & \text { Device Function Proxy } \\ \text { DIS } & \text { distributed interaction simulation } \\ \text { DM } & \text { Device Manager } \\ \text { DMU } & \text { digital mock-up } \\ \text { DMZ } & \text { demilitarised zone } \\ \text { DO } & \text { Device Observer } \\ \text { DP } & \text { Device Proxy } \\ \text { EA } & \text { expectation awareness } \\ \text { EDDL } & \end{array}$




\begin{tabular}{|c|c|}
\hline EM & Execution Manager \\
\hline $\mathrm{EN}$ & events notification \\
\hline ERP & Enterprise Resource Planning \\
\hline FB & function block \\
\hline FIPA & Foundation for Intelligent Physical Agents \\
\hline FMS & Flexible Manufacturing System \\
\hline GDP & gross domestic product \\
\hline GPS & global positioning system \\
\hline HLA & high-level architecture \\
\hline HMI & human machine interface \\
\hline HMS & Holonic Manufacturing System \\
\hline $\mathrm{I} / \mathrm{O}$ & Input/Output \\
\hline IC & integrated circuit \\
\hline IC & information collector \\
\hline ICT & information and communication technology \\
\hline IEC & International Electrotechnical Commission \\
\hline IM & instant messaging \\
\hline IMS & Intelligent Manufacturing System \\
\hline IRC & internet relay chat \\
\hline IRT & isochronous real time \\
\hline ISO & International Organisation for Standardisation \\
\hline JAKOBI & Java und komponentenbasierte Industriesteuerung \\
\hline JVM & Java virtual machine \\
\hline MAC & media access control \\
\hline MAP & manufacturing application protocol \\
\hline MAS & Multi-Agent System \\
\hline MASCADA & managing production change and disturbance \\
\hline MDE & Model-Driven Engineering \\
\hline MES & Manufacturing Execution System \\
\hline MMS & manufacturing message specification \\
\hline MOM & manufacturing operations management \\
\hline MRP & material requirements planning \\
\hline MWC & mobile wearable computing \\
\hline NO & node operator \\
\hline NTP & network time protocol \\
\hline $\mathrm{OA}$ & Order Agent \\
\hline OAS & Order Agent Supervisor \\
\hline $\mathrm{OO}$ & object orientation \\
\hline OSI & open systems interconnection \\
\hline $\mathrm{P} \& \mathrm{P}$ & plug \& participation \\
\hline PABADIS & Plant Automation Based on Distributed Systems \\
\hline PABADIS & PABADIS based Product Oriented Manufacturing Sys- \\
\hline PROMISE & tems for Re-Configurable Enterprises \\
\hline
\end{tabular}




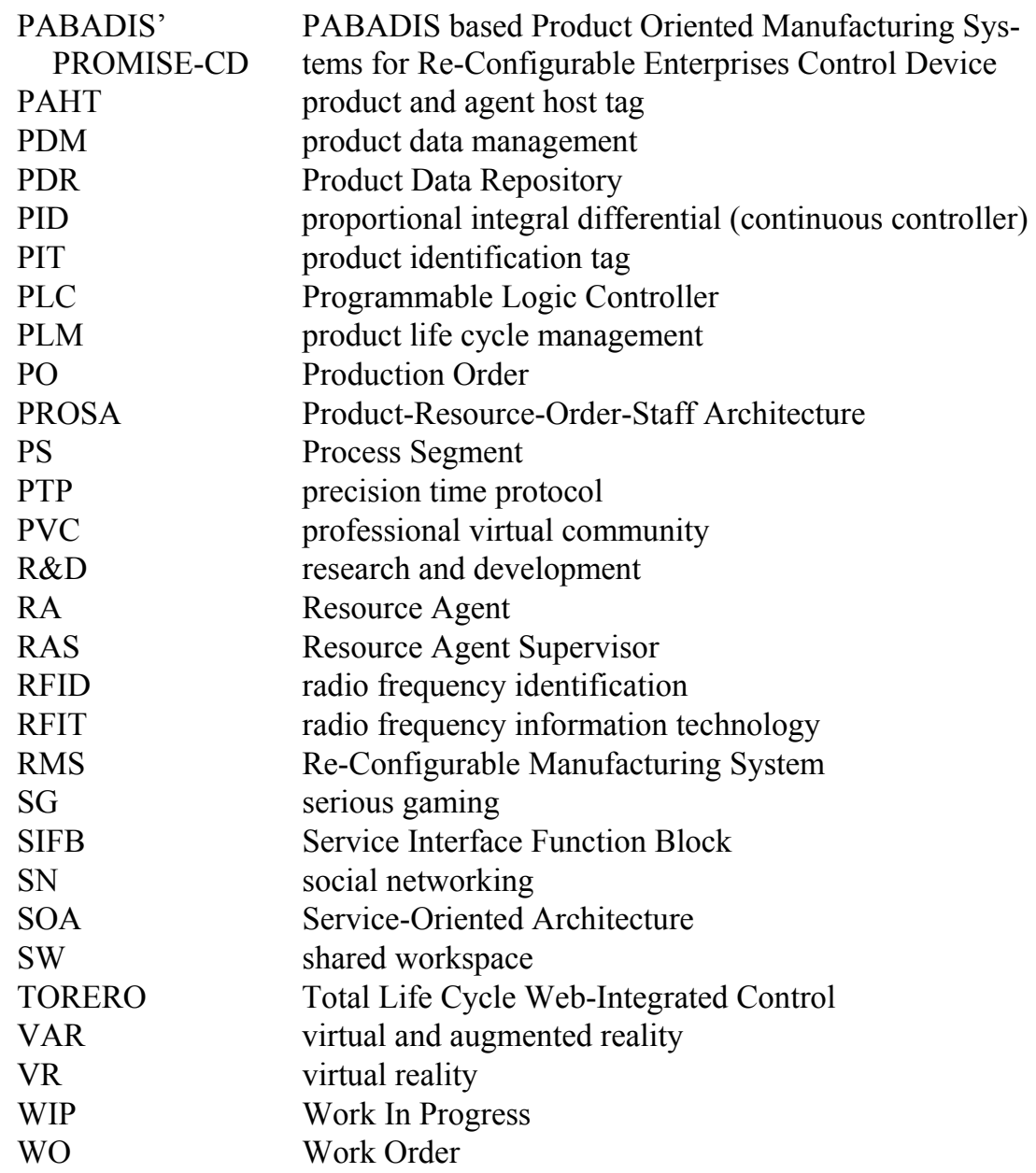




\section{About the Editor}

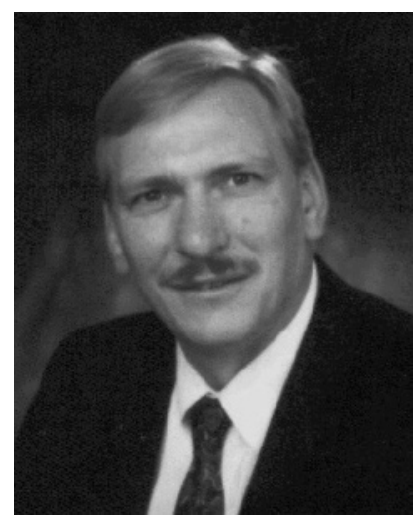

Hermann Kühnle holds a doctoral degree in mechanical engineering as well as a master's degree in mathematics, both from the University of Stuttgart. He joined the Otto-von-Guericke University Magdeburg, Germany, in 1994 as a full university professor for factory operations and production systems and as executive director of the Institute for Ergonomics, Manufacturing Systems and Automation, having previously served as lecturer, head of national applied research and responsible regional CIM coordinator and consultant. From 1994 to 2001 he was also foundation and executive director of the Fraunhofer Institute for Factory Operation and Automation, IFF, Magdeburg. Since 1995, Hermann Kühnle has been the spokesman for research on advanced production systems in Saxony-Anhalt. He is a member of boards of international journals, of companies and of venture capital groups. 